\title{
EDITORIAL
}

\section{Cooling via Trans-nasal High Flow Ambient Air: Does it Pass the Smell Test?}

\author{
Patrick M. Kochanek ${ }^{1,2,3,4^{*}}$ and Ericka L. Fink ${ }^{1,2}$
}

๑ 2019 Springer Science+Business Media, LLC, part of Springer Nature and Neurocritical Care Society

"When it snows in your nose you catch cold in your brain" [1]

\section{Allen Ginsberg}

In this issue of Neurocritical Care, Ziai et al. [2] present a novel and surprising exploratory report in seven patients demonstrating that high flow (maximum 50-60 L/min) application of ambient dry air provided by a nasal continuous positive airway pressure device can produce an initial reduction in core (esophageal) body temperature of $0.6 \pm 0.15{ }^{\circ} \mathrm{C}$ per hour in critically ill adults with persistent fever, defined as core temperature $>37.5^{\circ} \mathrm{C}$ for more than $24 \mathrm{~h}$ in the neuro-intensive care unit (ICU). This intervention was maintained for a period of $2 \mathrm{~h}$ at which time a $1.1{ }^{\circ} \mathrm{C}$ temperature reduction in core temperature was observed (from $38.4 \pm 0.6{ }^{\circ} \mathrm{C}$ at baseline to $37.3 \pm 0.5^{\circ} \mathrm{C}$ at $2 \mathrm{~h}$ ). A significant reduction in tympanic temperature was also seen at $2 \mathrm{~h}$, albeit somewhat smaller in magnitude $-0.6{ }^{\circ} \mathrm{C}$. Five of the seven patients achieved normothermia. These critically ill patients had a spectrum of underlying diseases including intracranial hemorrhage, intraventricular hemorrhage, anoxic brain injury, or transverse myelitis and were thus patients where either preventing or treating fever, maintaining normothermia, or inducing cooling might have clinical utility. It was also reported that the core temperature returned to baseline (febrile) within $30 \mathrm{~min}$ of discontinuing the intervention.

Although very exploratory and certainly pilot in nature, there are some intriguing findings in the study. First, the air used to induce cooling was ambient, not cold. Second,

\footnotetext{
*Correspondence: kochanekpm@pitt.edu

${ }^{1}$ Department of Critical Care Medicine, Safar Center for Resuscitation Research, University of Pittsburgh School of Medicine, UPMC Children's Hospital of Pittsburgh, John G. Rangos Research Center, 6th Floor, 4401 Penn Avenue, Pittsburgh, PA 15224, USA

Full list of author information is available at the end of the article
}

it is the energy required to evaporate nasal mucosal water that produced the temperature reduction, mandating the use of dry air. Third, cooling by this approach did not result in shivering in the patients-and none of the patients required anti-shivering agents or neuromuscular blockade. Safety of this approach, given the high flow exposure to the nasal mucosa of dry gas in these patients, was further assessed by an ear, nose and throat consultant as part of the team. This approach has been previously reported to be effective in pigs [3], and other related approaches such as the use of perfluorocarbon nasal sprays and/or nasal cooling balloons have also demonstrated success in patients and pigs, respectively $[4,5]$.

There are a number of potential limitations to this approach and this investigation. Assessment of safety certainly will require testing in a larger number of patients and over more extended periods than $2 \mathrm{~h}-$ unless only used with a brief exposure as an adjunct to other approaches and/or for acute treatment of refractory fever. Although a high flow nasal cannula approach is routinely used within the realm of noninvasive ventilator support in pediatric critical care medicine, where flow rates as high as $20-30 \mathrm{~L} / \mathrm{min}$ is used in older children, heated and humidified gas are used [6, 7]. In contrast, prolonged exposure of the nasal mucosa to such high flows of dry gas could be a concern. Also, the patients that might benefit the most from this type of approach are those who are not intubated, such as selected patients who are not comatose with stroke, particularly, if the observation that shivering was not seen with cooling by this nasal approach, is borne out in future studies. However, in this pilot report addressing feasibility, all but one patient was intubated, which limits an assessment of the spectrum of potential utility of the approach. Similarly, regarding shivering, in all but two of the subjects, the intervention treated fever-to achieve a state of normothermia-rather than

\section{Springer}


induce hypothermia, thus the amount of shivering that would be expected would likely be greater if this approach was applied to cool normothermic patients. Also, whether or not a patient who was alert and not intubated could tolerate $50-60 \mathrm{~L} / \mathrm{min}$ of high flow (and up to $20 \mathrm{~cm} \mathrm{H}_{2} \mathrm{O}$ of positive pressure) by nasal mask for sustained periods was not assessed. The possibility that this approach could produce untoward effects on venous return in the absence of a need for positive endexpiratory pressure, or contribute to aspiration in neurologically compromised patients merits exploration.

Longer exposure times would also be needed to determine if there were any other potential deleterious pulmonary effects of high dry gas flow in patients, where the airway was not protected from exposure by intubation. Exactly how refractory these patients were to conventional approaches to the treatment of fever in the neuroICU is also not fully outlined in this report-particularly given the vigilance in the treatment (or prevention) of fever in contemporary neurocritical care. Some patients were only shown to be refractory to acetaminophen. Approaches such as intravenous cooling catheters, surface cooling, and/or IV cold saline infusion are routinely used in neurocritical care [8-10], and although each has its own spectrum of efficacy and side effect profile, they are established methods that have established places in our therapeutic armamentarium, although the efficacy of some more broadly used treatments to control fever in the ICU, such as acetaminophen, has been challenged [11].

Finally, the magnitude of the effect of this approach on temperature reduction, despite the substantial air flow that was required, was somewhat modest-a $0.6{ }^{\circ} \mathrm{C}$ reduction in tympanic temperature. Presumably that monitor is the best reflection of brain temperature [11], although the best way to estimate brain temperature can be complex [12]. And although each degree of fever has been associated with greater unfavorable outcome in the setting of acute brain injury [13], the change in temperature produced by this approach is limited. Also whether the air flow (at ambient temperature) that was required might produce an overestimate of the actual reduction in core temperature, which was measured as esophageal temperature, remains to be determined.

In any case, it is somewhat remarkable that this intervention was able to successfully treat fever at the bedside-even in intubated patients. And although it is unclear yet whether or not this approach "passes the smell test", such an approach, given its simplicity, merits additional exploration-particularly, if fever was highly refractory in these cases. Whether or not the lack of shivering response would similarly be seen when applied to induce hypothermia rather than treat fever would seem to be one of the key questions to address in future studies to determine the breadth of its potential utility.

\begin{abstract}
Author details
${ }^{1}$ Department of Critical Care Medicine, Safar Center for Resuscitation Research, University of Pittsburgh School of Medicine, UPMC Children's Hospital of Pittsburgh, John G. Rangos Research Center, 6th Floor, 4401 Penn Avenue, Pittsburgh, PA 15224, USA. ${ }^{2}$ Department of Pediatrics, University of Pittsburgh School of Medicine, UPMC Children's Hospital of Pittsburgh, John G. Rangos Research Center, 6th Floor, 4401 Penn Avenue, Pittsburgh, PA 15224 USA. ${ }^{3}$ Department of Bioengineering, University of Pittsburgh School of Medicine, Pittsburgh, PA 15261, USA. ${ }^{4}$ Department of Clinical and Translational Science, University of Pittsburgh School of Medicine, Pittsburgh, PA 15261, USA.
\end{abstract}

\section{Author Contributions}

Both Drs. Kochanek and Fink authored and edited the manuscript.

\section{Source of Support}

There was no financial support to list from any funding agency, or other commercial source for either author for this editorial.

\section{Conflict of interest}

Dr. Kochanek is a co-inventor on US Patent US 8,628,512 B2, titled "Method of Inducing Emergency Preservation and Resuscitation (EPR) Following Cardiopulmonary Arrest" and is a co-inventors on a pending patent on the use of FGF21 therapy in temperature managed patients titled "Method to Improve Neurologic Outcomes in Temperature Managed Patients" (USPTO Application No. 15/573,006)

\section{Publisher's Note}

Springer Nature remains neutral with regard to jurisdictional claims in published maps and institutional affiliations.

Published online: 22 March 2019

\section{References}

1. http://famouspoetsandpoems.com/poets/allen_ginsberg/quotes. Accessed 7 Jan 2019

2. Ziai W, Shah D, Assis FR, Tandri H, Geocadin RG. Feasibility and safety of transnasal high flow air to reduce core body temperature in febrile neurocritical care patients. Neurocrit Care. 2019. https://doi.org/10.1007/ s12028-019-00702-x.

3. Chava R, Zviman M, Raghavan MS, et al. Rapid induction of therapeutic hypothermia using transnasal high flow dry air. Ther Hypothermia Temp Manag. 2017;7:50-6.

4. Norberg P, Taccone FS, Castren M, et al. Design of the PRINCESS trial; pre-hospital resuscitation intra-nasal cooling effectiveness survival study (PRINCESS). BMC Emerg Med. 2013;13:21.

5. Covaciu L, Allers M, Enblad P, Lunderquist A, Wieloch T, Rubertsson S. Intranasal selective brain cooling in pigs. Resuscitation. 2008;76:83-8.

6. Romans RA, Schwartz SM, Costello JM, et al. Epidemiology of noninvasive ventilation in pediatric cardiac ICUs. Pediatr Crit Care Med. 2017;18:949-57.

7. Kawaguchi A, Yasui Y, deCaen A, Garros D. The clinical impact of heated humidified high-flow nasal cannula on pediatric respiratory distress. Pediatr Crit Care Med. 2017:18:112-9.

8. Fink EL, Kochanek PM, Clark RS, Bell MJ. Fever control and application of hypothermia using intravenous cold saline. Pediatr Crit Care Med. 2012;13:80-4

9. Puccio AM, Fischer MR, Jankowitz BT, Yonas H, Darby JM, Okonkwo DO. Induced normothermia attenuates intracranial hypertension and reduces fever burden after severe traumatic brain injury. Neurocrit Care. 2009;11:82-7. 
10. Sonder P, Janssens GN, Beishuizen A, Henry CL, Rittenberger JC, Callaway CW, Dezfulian C, Polderman KH. Efficacy of different cooling technologies for therapeutic temperature management: a prospective intervention study. Resuscitation. 2018;124:14-20.

11. Ray S, Rogers L, Brown KL, Peters MJ. The effect of acetaminophen on temperature in critically ill children: a retrospective analysis of over 50,000 doses. Pediatr Crit Care Med. 2018;19:204-9.
12. Smith CM, Adelson PD, Chang YF, et al. Brain-systemic temperature gradient is temperature-dependent in children with severe traumatic brain injury. Pediatr Crit Care Med. 2011;12:449-54.

13. Laptook A, Tyson J, Shankaran S, et al. National Institute of Child Health and Human Development Neonatal Research Network. Elevated temperature after hypoxic-ischemic encephalopathy: risk factor for adverse outcomes. Pediatrics. 2008;122:491-9. 